\title{
Clinical significance of the sub-classification of 71 cases mucinous breast carcinoma
}

\author{
Shinichiro Kashiwagi ${ }^{1 *}$, Naoyoshi Onoda', Yuka Asano ${ }^{1}$, Satoru Noda ${ }^{1}$, Hidemi Kawajiri ${ }^{1}$, Tsutomu Takashima', \\ Masahiko Ohsawa², Seiichi Kitagawa ${ }^{3}$ and Kosei Hirakawa ${ }^{1}$
}

\begin{abstract}
Objective: Mucinous breast carcinoma (MBC) is classified into mixed mucinous breast carcinoma (MMBC) and pure mucinous breast carcinoma (PMBC) based on whether the tumor is with or without a component of invasive ductal carcinoma, respectively. PMBC is subtyped into hypocellular PMBC (PMBC-A) and hypercellular PMBC (PMBC-B).

Methods: Of 1,760 primary breast carcinomas, 71 were diagnosed as MBC, and were subtyped for comparison purposes.

Results: Seventy-one of all breast cancers (4.0\%) were MBC, and consisted of 23 MMBC, 32 PMBC-A and 16 PMBC-B. The MBC tumors were more often hormone receptor-positive and HER2-negative than non-MBC tumors. Patients with $M M B C, P M B C-B$ or $P M B C-A$, in this order, had significantly higher recurrence rates than non-MBC cases ( $p=0.006$, log-rank).

Conclusions: In the NCCN guidelines, MBC is also regarded as "a histological type with a favorable prognosis" in a uniform manner, and "treatment for a histological type with a favorable prognosis" is recommended. However, the results of this study suggest that sub-classification-based, individualized therapeutic strategies should be considered.
\end{abstract}

Keywords: Mucinous breast carcinoma; Subclassification; Breast cancer; Hypocellular variant; Hypercellular variant

\section{Introduction}

Mucinous breast carcinoma (MBC), a special type of breast carcinoma, is the second most common cancer after lobular carcinoma, accounting for $1.3-5.4 \%$ of all breast cancers (Ellis et al. 2003; Fentiman et al. 1977; Komaki et al. 1988; Scopsi et al. 1994; Anan et al. 2001). According to the current General Rules for Clinical and Pathological Recording of Breast Cancer, MBC is characterized by the fact that the cancer cells produce mucus, and nests of mucinous cancer cells occupy almost the entire tumor mass (Wilson et al. 1955). In the WHO classification of breast tumors, $\mathrm{MBC}$ is described as a subtype of mucinous carcinoma and other tumors with abundant mucus (mucin-producing carcinomas) (Ellis et al. 2003). It is histologically subtyped into mixed mucinous breast carcinoma (MMBC) containing a component of

\footnotetext{
*Correspondence: spqv9ke9@view.ocn.ne.jp

'Department of Surgical Oncology, Osaka City University Graduate School of Medicine, 1-4-3 Asahi-machi, Abeno-ku, Osaka, Japan

Full list of author information is available at the end of the article
}

conventional invasive ductal carcinoma, and pure mucinous breast carcinoma (PMBC), in which nests of mucinous cancer cells occupy almost the entire tumor mass, and which contains no component of conventional invasive ductal carcinoma (Capella et al. 1980; Ranade et al. 2010; Rosen 2008; André et al. 1995). PMBC may be subtyped into a hypocellular variant (PMBC-A) showing a tubular, cribriform, cord-like, micropapillary or papillary growth pattern, and a hypercellular variant (PMBC-B) growing in solid nests (Capella et al. 1980; Ranade et al. 2010). In this study, we clinicopathologically analyzed MBC according to these subtypes.

\section{Materials and methods \\ Patient background}

A total of 1,760 patients with primary breast cancer underwent surgery between January 2000 and December 2012. Of these patients, 71 (4.0\%) were diagnosed with $\mathrm{MBC}$. These $\mathrm{MBC}$ cases were subtyped into $\mathrm{MMBC}$, $\mathrm{PMBC}-\mathrm{A}$ and $\mathrm{PMBC}-\mathrm{B}$ for comparison purposes. The 
median follow-up period was 7.8 years (range, $0.5-$ 10.1 years).

\section{Immunohistochemistry}

The hormone receptor (HR), human epidermal growth factor receptor 2 (HER2) expression and proliferative activity, as measured by the Ki67 labeling index, were evaluated by immunohistochemical staining of formalinfixed, paraffin-embedded surgical breast cancer specimens using the $\mathrm{ABC}$ method. For antigen activation, deparaffinized sections were immersed in $0.01 \mathrm{M}$ citrate buffer ( $\mathrm{pH}$ 6.0), and heated at $105^{\circ} \mathrm{C}$ for $10 \mathrm{~min}$. Primary antibodies against the ER (clone 1D5, dilution 1:80; Dako, Carpinteria, California, USA), PR (clone PgR636, dilution 1:100; Dako), HER2 (Hercep Test ${ }^{\mathrm{Tw}}$, Dako) and Ki67 (clone MIB-1, dilution 1:100; Dako) were used. Endogenous peroxidase activity was blocked with $0.3 \%$ $\mathrm{H}_{2} \mathrm{O}_{2}$ in methanol, color was developed with DAB (3, 3diaminobenzidine, tetrahydrochloride) and the sections were counterstained with Meyer's hematoxylin. A pathological diagnosis was made by two pathologists who specialized in mammary gland pathology using the blind method to confirm the objectivity and reproducibility of the diagnosis.

\section{Immunohistochemical scoring}

For the hormone receptors, any staining was considered to indicate a positive sample. HER2 reactivity was assessed according to the ASCO/CAP guidelines. The Ki67 labeling index was evaluated as a percentage of positive cells among more than 1,000 cancer cells in five high-powered fields (HPFs) of the deepest portion and margin of the superficial layer of the tumor, and a percentage of $14 \%$ or higher was considered to be positive.

\section{Statistical analysis}

Statistical analysis was performed using SPSS version 13.0 statistical software (IBM, Armonk, New York, USA). Clinicopathological factors were analyzed in MBC patients using the chi-square test. Disease-free survival rates were calculated using the Kaplan-Meier method, and significance was assessed using the log-rank test. A value of $\mathrm{p}<0.05$ was considered to be significant.

\section{Results}

Of the 1,760 patients who underwent surgery for primary breast cancer, 71 (4.0\%), 23 (32.4\%), 32 (45.1\%) and 16 (22.5\%) had MBC, MMB, PMBC-A and PMBC-B, respectively. Table 1 shows their clinicopathological characteristics. Their mean age was 61.8 years (range, 26-95 years; median, 64 years). The mean tumor diameter was $3.1 \mathrm{~cm}$ (range, $0.5-12.3 \mathrm{~cm}$; median, $2.5 \mathrm{~cm}$ ). Eight (11.3\%), fifteen $(21.1 \%)$, and 31 patients (43.7\%) had lymph node metastasis, vascular invasion and an extensive
Table 1 Demographical data of 71 patients with mucinous carcinoma of the breast

\begin{tabular}{|c|c|}
\hline Parameters $(n=71)$ & Percentage \\
\hline Age & mean $61.8(26-95$, median 64$)$ \\
\hline Tumor diameter $(\mathrm{cm})$ & mean 3.1 (0.5 - 12.3, median 2.5) \\
\hline Tumor location & $39(54.9 \%) / 32(45.1 \%)$ \\
\hline \multicolumn{2}{|l|}{ right/left } \\
\hline Subtype & $\begin{array}{c}23(32.4 \%) / 32(45.1 \%) / \\
16(22.5 \%)\end{array}$ \\
\hline \multicolumn{2}{|l|}{ MMBC/PMBC-A / PMBC-B } \\
\hline Pathological stage & $\begin{array}{c}23(32.4 \%) / 40(56.3 \%) / \\
8(11.3 \%)\end{array}$ \\
\hline \multicolumn{2}{|l|}{$|/||/|||$} \\
\hline pT & $\begin{array}{c}23(32.4 \%) / 38(53.5 \%) / \\
6(8.5 \%) / 4(5.6 \%)\end{array}$ \\
\hline \multicolumn{2}{|l|}{$\mathrm{T} 1 / \mathrm{T} 2 / \mathrm{T} 3 / \mathrm{T} 4$} \\
\hline pLymph node status & $8(11.3 \%) / 63(88.7 \%)$ \\
\hline \multicolumn{2}{|l|}{ Positive/Negative } \\
\hline Lymphovascular invasion & $15(21.1 \%) / 56(78.9 \%)$ \\
\hline \multicolumn{2}{|l|}{ Positive/Negative } \\
\hline Nuclear grade & $\begin{array}{c}55(77.5 \%) / 15(21.1 \%) / \\
1(1.4 \%)\end{array}$ \\
\hline \multicolumn{2}{|l|}{$1 / 2 / 3$} \\
\hline $\mathrm{EIC}$ & $31(43.7 \%) / 40(56.3 \%)$ \\
\hline \multicolumn{2}{|l|}{ Positive/Negative } \\
\hline Hormone receptor status & $68(95.8 \%) / 3(4.2 \%)$ \\
\hline \multicolumn{2}{|l|}{ Positive/Negative } \\
\hline HER 2 status & $1(1.4 \%) / 70(98.6 \%)$ \\
\hline \multicolumn{2}{|l|}{ Positive/Negative } \\
\hline Ki67 & $8(11.3 \%) / 63(88.7 \%)$ \\
\hline \multicolumn{2}{|l|}{ Positive/Negative } \\
\hline Recurrence & 7 (9.9\%)/64 (90.1\%) \\
\hline \multicolumn{2}{|l|}{ Recurrence/no- Recurrence } \\
\hline Recurrence cases $(n=7)$ & $6(85.7 \%) / 0(0.0 \%) / 1(14.3 \%)$ \\
\hline MMBC/PMBC-A/PMBC-B & \\
\hline
\end{tabular}

$\overline{M M B C}$ mixed mucinous carcinoma, $P M B C$ pure mucinous carcinoma, EIC extensive intraductal component.

intraductal component (EIC), respectively. Breast cancer subtyping based on the hormone receptor (HR) and HER2 expression showed that, of the 71 tumors, 68 (95.8\%), one (1.4\%) and two (2.8\%) were HR-positive/ HER2-negative, HR-negative/HER2-postive and HRnegative/HER2-negative (so-called triple-negative), respectively. Of the seven patients with recurrence, six (85.7\%) had MMBC, none had PMBC-A, one (14.3\%) had PMBC-B, and none of the patients had died.

The clinicopathological analysis revealed that MBCs had a significantly larger diameter than non-MBCs $(\mathrm{p}=0.001)$, and were significantly more frequently HR-positive $(\mathrm{p}<0.001)$ 
Table 2 Clinicopathologic feature of 71 mucinous breast cancers in 1760 breast carcinomas

\begin{tabular}{|c|c|c|c|}
\hline Parameters & $M B C(n=71)$ & Non-MBC $(n=1689)$ & $\mathrm{p}$ value \\
\hline Age at operation & $38(53.5 \%)$ & $965(57.1 \%)$ & 0.547 \\
\hline$\leq 64$ & $33(46.5 \%)$ & 724 (42.9\%) & \\
\hline \multicolumn{4}{|l|}{$>64$} \\
\hline Pathological stage & $23(32.4 \%)$ & 799 (47.3\%) & 0.014 \\
\hline I & $48(67.6 \%)$ & $890(52.7 \%)$ & \\
\hline \multicolumn{4}{|l|}{ II and III } \\
\hline pTumor size & $25(35.2 \%)$ & 937 (55.5\%) & 0.001 \\
\hline$\leq 2 \mathrm{~cm}$ & $46(64.8 \%)$ & $752(45.5 \%)$ & \\
\hline \multicolumn{4}{|l|}{$>2 \mathrm{~cm}$} \\
\hline pLymph node status & $63(88.7 \%)$ & $1270(75.2 \%)$ & 0.009 \\
\hline Negative & $8(11.3 \%)$ & 419 (24.8\%) & \\
\hline \multicolumn{4}{|l|}{ Positive } \\
\hline Lymphovascular invasion & $56(78.9 \%)$ & $1276(75.5 \%)$ & 0.522 \\
\hline Negative & $15(21.1 \%)$ & $413(24.5 \%)$ & \\
\hline \multicolumn{4}{|l|}{ Positive } \\
\hline HR (ER and/or PR) & $3(4.2 \%)$ & 477 (28.2\%) & $<0.001$ \\
\hline Negative & $68(95.8 \%)$ & $1212(71.8 \%)$ & \\
\hline \multicolumn{4}{|l|}{ Positive } \\
\hline HER 2 status & $70(98.6 \%)$ & $1310(77.6 \%)$ & $<0.001$ \\
\hline Negative & $1(1.4 \%)$ & $379(22.4 \%)$ & \\
\hline Positive & & & \\
\hline
\end{tabular}

$M B C$ mucinous breast carcinoma.

$H R$ Hormone receptor. and negative for HER2 overexpression $(\mathrm{p}<0.001)$ (Table 2).

Among all patients $(n=1,760)$, there was no significant difference in the DFS between those with MBC and those with non-MBC tumors $(\mathrm{p}=0.614, \log$-rank test) (Figure 1a). However, a subtype analysis showed that patients with $\mathrm{MMBC}$, $\mathrm{PMBC}-\mathrm{B}$ or $\mathrm{PMBC}-\mathrm{A}$, in this order, had a significantly higher recurrence rate than those with non-MBC tumors $(\mathrm{p}=0.006$, log-rank test) (Figure $1 \mathrm{~b})$. Among the $71 \mathrm{MBCs}$, MMBC showed a significantly higher Ki67 labeling index $(\mathrm{P}=0.010)$ and nuclear grade $(\mathrm{p}<0.001)$ than PMBC, and these were not correlated with the HR or HER2 expression (Table 3). Among the 48 PMBCs, no significant differences in the clinicopathological characteristics were noted between patients with PBMC-A and those with PMBC-B.

The patients with recurrence were divided into those with and without lymph node metastasis, and their primary tumors and metastatic lymph nodes were pathologically examined. As a result, other pathological types coexisting with MBC (Figure 2a) were also confirmed to be present in the metastatic lymph nodes (Figure 2b). A mucus-rich lesion, as seen in the primary tumor (Figure 2c), was also observed in the metastatic lymph nodes (Figure 2d) of the patients with PMBC-A who had no recurrence in the presence of lymph node metastasis.

\section{Discussion}

It has been reported that $\mathrm{MBC}$ shows a favorable prognosis, with a 10-year survival rate of more than $90 \%$ (Fentiman et al. 1977; Komaki et al. 1988; Di Saverio et al. 2008). Since a higher ratio of the extracellular mucus

\section{All breast carcinomas $(n=1760)$}

\section{Mucinous breast carcinomas $(n=71)$}

\section{Disease Free Survival}
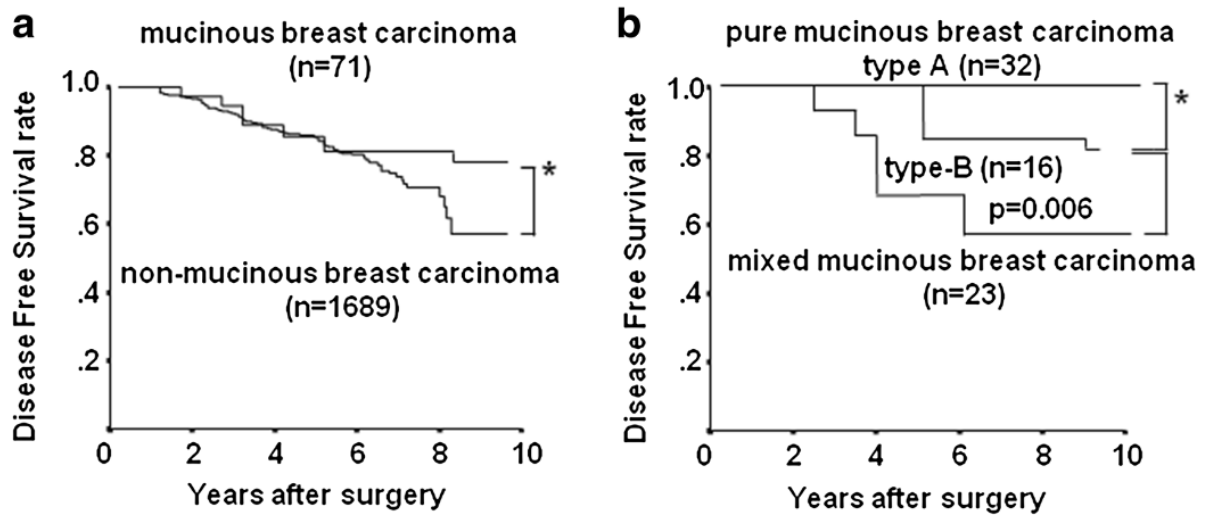

Figure 1 Correlation between the mucinous carcinoma phenotype and disease-free survival in the breast cancer series. The mixed mucinous breast carcinoma patients experienced significantly poorer outcomes in all breast cancers (a) and mucinous carcinomas (b). (NS; not significant). 
Table 3 Correlations between subtype and clinicopathological parameters in $\mathbf{7 1}$ mucinous breast carcinomas

\begin{tabular}{|c|c|c|c|c|c|c|}
\hline \multirow[t]{2}{*}{ Parameters } & \multicolumn{2}{|c|}{ MBC $(n=71)$} & \multirow[t]{2}{*}{$p$ value } & \multicolumn{2}{|c|}{ PMBC $(n=48)$} & \multirow[t]{2}{*}{$\mathrm{p}$ value } \\
\hline & MMBC $(n=23)$ & PMBC $(n=48)$ & & PMBC-A $(n=32)$ & PMBC-B $(n=16)$ & \\
\hline Age at operation & $14(60.9 \%)$ & $24(50.0 \%)$ & 0.390 & $14(43.8 \%)$ & $10(62.5 \%)$ & 0.220 \\
\hline$\leq 64$ & 9 (39.1\%) & $24(50.0 \%)$ & & $18(56.2 \%)$ & $6(37.5 \%)$ & \\
\hline \multicolumn{7}{|l|}{$>64$} \\
\hline Pathological stage & 9 (39.1\%) & $14(29.2 \%)$ & 0.401 & $8(25.0 \%)$ & $6(37.5 \%)$ & 0.369 \\
\hline I & $14(60.9 \%)$ & $34(70.8 \%)$ & & $24(75.0 \%)$ & $10(62.5 \%)$ & \\
\hline \multicolumn{7}{|l|}{$\|$ and III } \\
\hline pTumor size & $11(47.8 \%)$ & $14(29.2 \%)$ & 0.123 & $8(25.0 \%)$ & $6(37.5 \%)$ & 0.175 \\
\hline$\leq 2 \mathrm{~cm}$ & $12(52.2 \%)$ & $34(70.8 \%)$ & & $24(75.0 \%)$ & $10(62.5 \%)$ & \\
\hline \multicolumn{7}{|l|}{$>2 \mathrm{~cm}$} \\
\hline pLymph node status & 19 (82.6\%) & $44(91.7 \%)$ & 0.162 & $30(93.8 \%)$ & $14(87.5 \%)$ & 0.460 \\
\hline Negative & $4(17.4 \%)$ & $4(8.3 \%)$ & & $2(6.2 \%)$ & $2(12.5 \%)$ & \\
\hline \multicolumn{7}{|l|}{ Positive } \\
\hline Lymphovascular invasion & $16(69.6 \%)$ & $40(83.3 \%)$ & 0.184 & $29(90.6 \%)$ & $11(68.8 \%)$ & 0.057 \\
\hline Negative & $7(30.4 \%)$ & $8(16.7 \%)$ & & $3(9.4 \%)$ & $5(32.2 \%)$ & \\
\hline \multicolumn{7}{|l|}{ Positive } \\
\hline HR (ER and / or PR) & $1(4.3 \%)$ & $2(4.2 \%)$ & 0.454 & $1(3.1 \%)$ & $1(6.3 \%)$ & 0.453 \\
\hline Negative & $22(95.7 \%)$ & $46(95.8 \%)$ & & 31 (96.9\%) & 15 (93.7\%) & \\
\hline \multicolumn{7}{|l|}{ Positive } \\
\hline HER2 status & $23(100.0 \%)$ & 47 (97.9\%) & 0.676 & 31 (96.9\%) & 16 (100.0\%) & 0.667 \\
\hline Negative & $0(0.0 \%)$ & $1(2.1 \%)$ & & 1 (3.1\%) & $0(0.0 \%)$ & \\
\hline \multicolumn{7}{|l|}{ Positive } \\
\hline Ki67 & 17 (73.9\%) & $46(95.8 \%)$ & 0.010 & 30 (93.8\%) & 16 (100.0\%) & 0.439 \\
\hline Negative & $6(26.1 \%)$ & $2(4.2 \%)$ & & $2(6.2 \%)$ & $0(0.0 \%)$ & \\
\hline \multicolumn{7}{|l|}{ Positive } \\
\hline Nuclear grade & $11(47.8 \%)$ & 44 (91.7\%) & $<0.001$ & 30 (93.8\%) & $14(87.5 \%)$ & 0.306 \\
\hline 1 & $12(52.2 \%)$ & $4(8.3 \%)$ & & $2(6.2 \%)$ & $2(22.5 \%)$ & \\
\hline \multicolumn{7}{|l|}{2 and 3} \\
\hline $\mathrm{EIC}$ & $12(52.2 \%)$ & $28(58.3 \%)$ & 0.624 & $20(62.5 \%)$ & $8(50.0 \%)$ & 0.174 \\
\hline Negative & $11(47.8 \%)$ & $20(41.7 \%)$ & & $12(37.5 \%)$ & $8(50.0 \%)$ & \\
\hline Positive & & & & & & \\
\hline
\end{tabular}

BMC breast mucinous carcinoma, MMBC mixed mucinous carcinoma, PMBC pure mucinous carcinoma, HR Hormone receptor, EIC extensive intraductal component.

component to the cancer cell component is associated with a more favorable prognosis, PMBC-A, PMBC-B and $M M B C$, in this order, would be expected to show a favorable prognosis (Komaki et al. 1988; Ranade et al. 2010; Clayton 1986). In this study, there was no significant difference in the DFS between the patients with MBC and those with non-MBC tumors. However, a subtype analysis showed that patients with MMBC had a significantly higher recurrence rate than those with $\mathrm{PMBC}$, suggesting the usefulness of breast cancer sub-classification.

Of the seven patients with recurrence in the present study, six (85.7\%) had MMBC, none had PMBC-A and one (14.3\%) had PMBC-B. Of the eight patients with lymph node metastasis, four (three with $\mathrm{MMBC}$ and one with $\mathrm{PMBC}-\mathrm{B}$ ) had recurrence. On the other hand, two patients with PMBC-A had no recurrence in the presence of lymph node metastasis. This suggests that PMBC-A with a high proportion of mucus shows a favorable prognosis even in the presence of lymph node metastasis.

From the viewpoint of the intrinsic subtype, MBC tumors were frequently HR-positive/HER2-negative, and often of the so-called luminal A type (Ki67 labeling index $<14 \%$ ). Many researchers have reported that most $\mathrm{MBCs}$ are luminal A type, and that this is a clinicopathological characteristic of MBC (Komaki et al. 1988; 


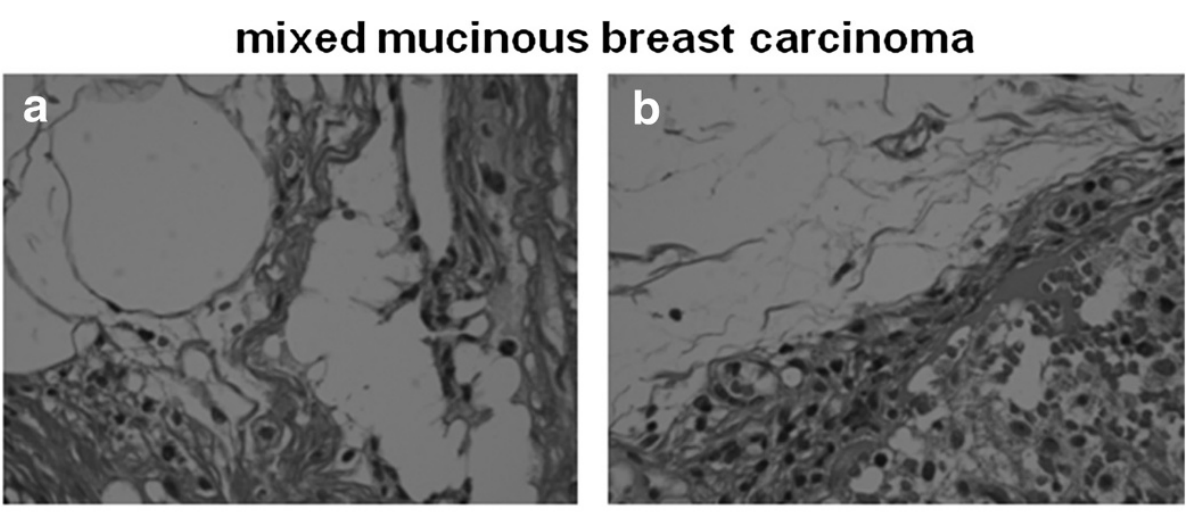

\section{pure mucinous breast carcinoma type $A$}
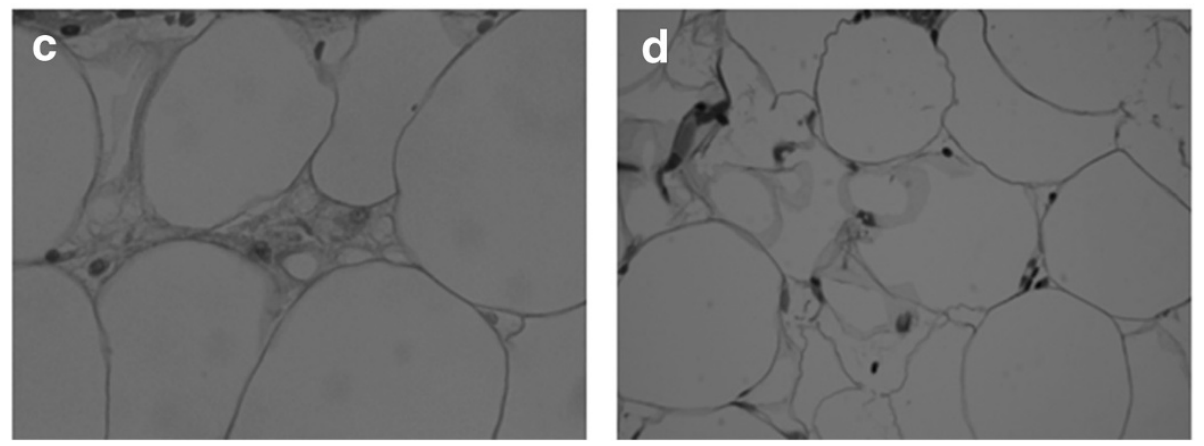

Figure 2 Histological findings (H.E. stain $\mathbf{x}$ 400). (a) primary lesion of mixed mucinous breast carcinoma. (b) metastatic lymph node of mixed mucinous breast carcinoma. (c) primary lesion of pure mucinous breast carcinoma type A. (d) metastatic lymph node of pure mucinous breast carcinoma type A.

Diab et al. 1999; Cao et al. 2012; Shousha et al. 1989). Hormone therapy is a common treatment option used for patients with luminal A-type breast cancer, but some MBCs are resistant to treatment, suggesting that MMBC, which are considered to have a relatively poor prognosis based on the present results, may have different biological properties even within the same tumor type.

Thus, with regard to the therapeutic strategies based on the sub-classification of mucinous carcinoma of the mammary gland, "standard treatment" for a coexisting histological type should be performed in patients with MMBC, which shows a high recurrence rate (NCCN Clinical Practice Guidelines in Oncology Breast Cancer v.2 2012). Among patients with PMBC, "standard treatment" or "treatment for a histological type with a favorable prognosis" should be selected based on the presence or absence of lymph node metastasis in those with PMBC-B. On the other hand, in those with PMBC-A, "treatment for a histological type with a favorable prognosis" may be selected, regardless of the presence or absence of lymph node metastasis.

In the NCCN guidelines, $\mathrm{MBC}$ is also regarded as "a histological type with a favorable prognosis" in a uniform manner, and "treatment for a histological type with a favorable prognosis" is recommended. However, the results of this study suggest that sub-classification-based, individualized therapeutic strategies should therefore be considered.

\section{Competing interests}

The all of authors have no conflicts of interest to disclose.

\section{Authors' contributions}

SK participated in the design of the study and drafted the manuscript. NO helped with study data collection and manuscript preparation. YA, SN, HK, TT helped with study data collection and participated in its design. MO helped with data collection and manuscript preparation. SK, KH conceived of the study, and participated in its design and coordination and helped to draft the manuscript. All have read and approved the final manuscript.

\section{Author details}

'Department of Surgical Oncology, Osaka City University Graduate School of Medicine, 1-4-3 Asahi-machi, Abeno-ku, Osaka, Japan. ${ }^{2}$ Deaprtment of

Diagnostic Pathology, Osaka City University Graduate School of Medicine, 1-4-3 Asahi-machi, Abeno-ku, Osaka, Japan. ${ }^{3}$ Deaprtment of Physiology, Osaka City University Graduate School of Medicine, 1-4-3 Asahi-machi, Abeno-ku, Osaka, Japan.

Received: 14 September 2013 Accepted: 17 September 2013 Published: 23 September 2013 


\section{References}

Anan K, Mitsuyama S, Tamae K, Nishihara K, Iwashita T, Abe Y, Ihara T, Nakahara S, Katsumoto F, Toyoshima S (2001) Pathological features of mucinous carcinoma of the breast are favorable for breast-conserving therapy. Eur J Surg Oncol 27:459-463

André S, Cunha F, Bernardo M, Meneses E, Sousa J, Cortez F, Soares J (1995) Mucinous carcinoma of the breast: a pathologic study of 82 cases. J Surg Oncol 58:162-167

Cao AY, He M, Liu ZB, Di GH, Wu J, Lu JS, Liu GY, Shen ZZ, Shao ZM (2012) Outcome of pure mucinous breast carcinoma compared to infiltrating ductal carcinoma: a population-based study from China. Ann Surg Oncol 19:3019-3027

Capella C, Eusebi V, Mann B, Azzopardi JG (1980) Endocrine differentiation in mucoid carcinoma of the breast. Histopathology 4:613-630

Clayton F (1986) Pure mucinous carcinomas of breast: morphologic features and prognostic correlates. Hum Pathol 17:34-38

Di Saverio S, Gutierrez J, Avisar E (2008) A retrospective review with long term follow up of 11,400 cases of pure mucinous breast carcinoma. Breast Cancer Res Treat 111:541-547

Diab SG, Clark GM, Osborne CK, Libby A, Allred DC, Elledge RM (1999) Tumor characteristics and clinical outcome of tubular and mucinous breast carcinomas. J Clin Oncol 17:1442-1448

Ellis IO, Schnitt SJ, Sastre-Garau X (2003) Invasive breast carcinoma. In: Tavassoli FA, Devilee P (ed) Pathology and Genetics of Tumours of the Breast and Female Genital Organs. World Health Organization Classification of Tumours. IARC Press, Lyon, pp 13-59

Fentiman IS, Millis RR, Smith P, Ellul JP, Lampejo O (1977) Mucoid breast carcinoma: histology and prognosis. Br J Cancer 75:1061-1065

Komaki K, Sakamoto G, Sugano H, Morimoto T, Monden Y (1988) Mucinous carcinoma of breast in Japan. A prognostic analysis based on morphologic features. Cancer 61:989-996

NCCN Clinical Practice Guidelines in Oncology Breast Cancer v.2 (2012). Accessed October 31, 2012, at http://www.nccn.org/professionals/physician_gls/PD/ breast.pdf

Ranade A, Batra R, Sandhu G, Chitale RA, Balderacchi J (2010) Clinicopathological evaluation of 100 cases of mucinous carcinoma of the breast with emphasis on axillary staging and special reference to a micropapillary pattern. J Clin Pathol 63:1043-1047

Rosen PP (2008) Rosen`s Breast Pathology, 3rd edition. Lippincott Williams \& Wilkins, Philadelpha, pp p515-535

Scopsi L, Andreola S, Pilotti S, Bufalino R, Baldini MT, Testori A, Rilke F (1994) Mucinous carcinoma of the breast. A clinicopathologic, histochemical, and immunocytochemical study with special reference to neuroendocrine differentiation. Am J Surg Pathol 18:702-711

Shousha S, Coady AT, Stamp T, James KR, Alaghband-Zadeh J (1989) Oesterogen receptors in mucinous carcinoma of the breast: an immunohistological study using paraffin wax sections. J Clin Pathol 42:902-905

Wilson TE, Helvie MA, Oberman HA, Joynt LK (1955) Pure and mixed mucinous carcinoma of the breast: pathologic basis for differences in mammographic appearance. AJR Am J Rogentgenol 1651:285-289

doi:10.1186/2193-1801-2-481

Cite this article as: Kashiwagi et al: Clinical significance of the subclassification of 71 cases mucinous breast carcinoma. SpringerPlus 2013 2:481.

\section{Submit your manuscript to a SpringerOpen ${ }^{\circ}$ journal and benefit from:}

- Convenient online submission

- Rigorous peer review

- Immediate publication on acceptance

- Open access: articles freely available online

- High visibility within the field

- Retaining the copyright to your article

Submit your next manuscript at $\gg$ springeropen.com 